\title{
La pintura mural en la Granada del XVIII
}

\author{
Ana María Gómez Román \\ Universidad de Granada \\ amaroman@ugr.es
}

RESUMEN: El camino hacia la revalorización de la pintura mural a lo largo del siglo XVIII en la ciudad de Granada arranca con la figura del arzobispo Martín de Ascargorta (1693-1719). El gusto impuesto por este prelado supuso un cambio durante la primera mitad de este siglo en el desarrollo de los programas decorativos bajo las directrices de Acisclo Antonio Palomino y José Risueño que tendría su prolongación con la actividad de pintores como Martín de Pineda, José Hidalgo, Diego Sánchez Saravia o Tomás Ferrer. Este gusto por la pintura mural culminaría a finales de la centuria con el ciclo de las hazañas del Quijote del Palacio del Cuzco en Víznar, relacionado también con otro arzobispo, Juan Manuel Moscoso (1789-1811) y realizado por Nicolás Martín Tenllado, José de Medina y Antonio Jiménez.

PALABRAS CLAVE: Pintura mural, Acisclo Antonio Palomino, José Risueño, Juan de Medina, José Hidalgo, Tomás Ferrer, Diego Sánchez Sarabia, Palacio del Cuzco (Víznar).

\section{The Mural Paintings in Eighteenth-Century Granada}

ABSTRACT: The route to the increase in value of mural painting throughout the $18^{\text {th }}$ century in the city of Granada begins with the figure of the Archbishop Martin de Ascargorta (1693-1719). The taste imposed by this prelate meant a change in the development of the decorative programs during the first half of this century under the guidance of Ascisclo Antonio Palomino and José Risueño which would be further extended with the activity of painters such as Martín de Pineda, José Hidalgo, Diego Sánchez Saravia or Tomás Ferrer. This taste for wall painting culminated at the end of the century in the cycle of the exploits of Don Quixote in the Palace of Cuzco in Víznar, also linked to another Archbishop, Juan Manuel Moscoso (1789-1811) and carried out by Nicolás Martín Tenllado, José de Medina and Antonio Jiménez.

KEYWORDS: Wall Painting, Acisclo Antonio Palomino, José Risueño, Juan de Medina, José Hidalgo, Tomás Ferrer, Diego Sánchez Sarabia, Palace of Cuzco (Víznar).

Recibido: 14 de abril de 2016 / Aceptado: 3 de junio de 2016.

El auge de la pintura mural en el XVIII arranca con la figura del arzobispo Martín de Ascargorta (1693-1719). El gusto impuesto por este prelado supuso un cambio en el desarrollo de los programas decorativos durante la primera mitad de esta centuria. Este mecenas de las artes azuzado por los ciclos programáticos emprendidos en otras urbes -en especial en el ámbito cortesano tras la llegada en 1692 de Luca Giordano y su participación en El Escorial, el Casón del Buen Retiro, el camarín de la Virgen de Atocha o la bóveda de la Sacristía de la Catedral de Toledo- impuso un nuevo planteamiento estético en el interior de determinados espacios religiosos basado en el ornato y el embellecimiento de los mismos. Fue así como dicho arzobispo sugirió el nombre del pintor Acisclo Antonio Palomino (1655-1726) como candidato para pintar la cúpula de la nave mayor del templo metropolitano. Si bien el programa catedralicio no se llevó a cabo permitió que el nombre del artista de Bujalance quedara definitivamente vinculado con Granada. De hecho, el primer ciclo mural programático se desarrolló en la cúpula del sancta sanctorum del monasterio de la Cartuja a partir de 1712 y bajo la dirección del expresado pintor quien, auxiliado por José Risueño, creó todo un completo programa iconográfico en torno a la figura de san Bruno [1]. Es por

GÓMEZ ROMÁN, Ana María: «La pintura mural en la Granada del XVIIl», Boletín de Arte, n. ${ }^{3}$ 37, Departamento de Historia del Arte, Universidad de Málaga, 2016, pp. 103-114, ISSN: 0211-8483. 


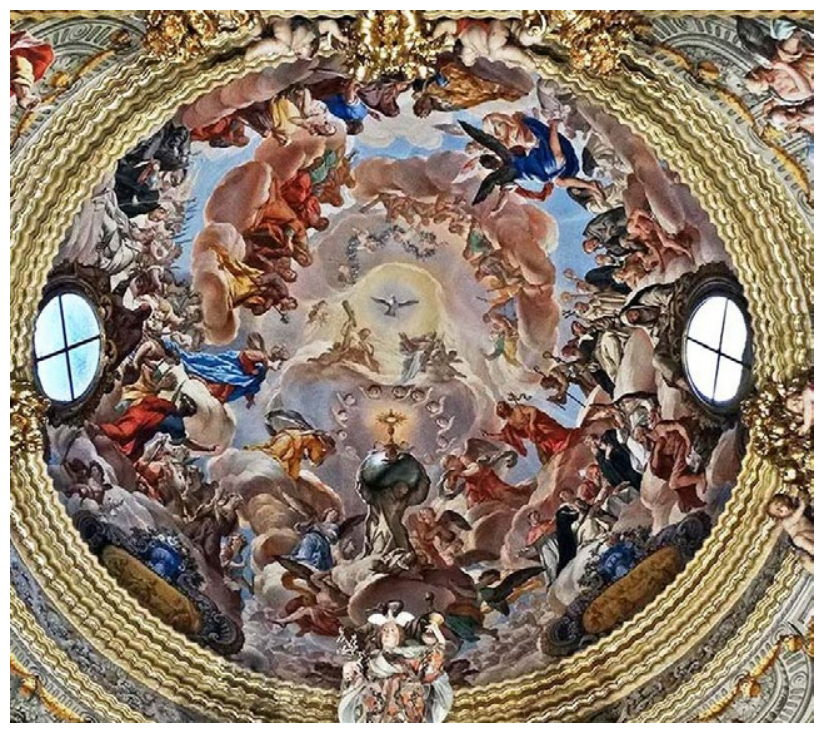

1. Acisclo Antonio Palomino, El triunfo de la Iglesia militante, 1712. Sancta sanctorum, Monasterio de la Cartuja, Granada. Foto: J. M. Rodríguez

2. Eduardo y Francisco Martínez, Pinturas murales (detalle), 1738. Monasterio de Santa Isabel la Real, Granada. Foto: J. M. Rodríguez

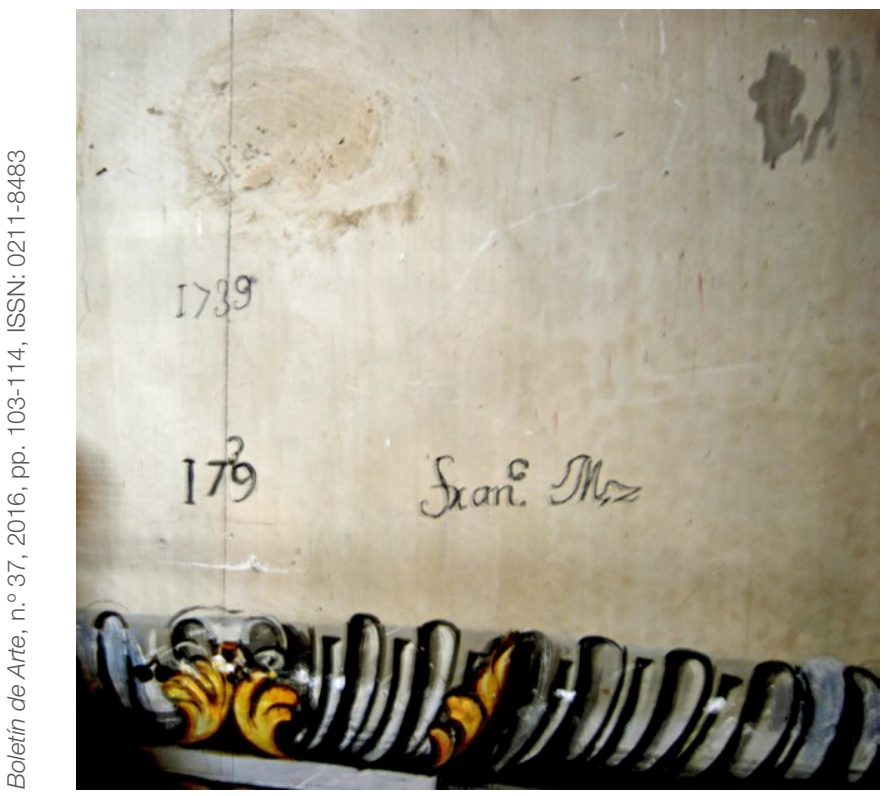

ello que la llegada de Palomino supondría un revulsivo para este tipo de práctica que tendría su continuidad más allá de mediados de siglo.

A todas luces, la decoración mural experimentó un considerable auge a finales del siglo XVII y sobre todo en la primera mitad del XVIII manteniendo su preeminencia a lo largo de esta centuria gracias a la demanda de una abultada clientela, vinculada fundamentalmente a la iglesia, que apostó por renovar algunos de los muchos espacios religiosos de la diócesis. Entre los pintores que se decantaron por esta modalidad artística los hay con cierta fama pero también otros tantos de los que apenas tenemos referencia alguna. Este es el caso de fray Francisco Figueroa que ejecutó a finales del XVII un Cristo ante los doctores en los muros de la segunda capilla del lado de la epístola de la iglesia conventual de Santo Domingo (Ceán Bermúdez, 1800: 118). Tampoco disponemos de muchas referencias de Eduardo y Francisco Martínez quienes entre 1738 y 1739 ejecutaron la decoración mural del presbiterio de la iglesia del monasterio de Santa Isabel la Real. Dichas pinturas, cuyas firmas se aprecian en uno de los muros, están realizadas con la técnica al seco simulando una arquitectura fingida que enmarca, a su vez, escenas narrativas, ramos de flores, ángeles y santos $^{1}$ [2-4]. Los pintores, a quienes consideramos padre e hijo, desarrollaron un programa de efectos ilusorios muy del gusto de la época. Sabemos que Francisco había nacido hacia 1706 y que alcanzó el grado de maestro como pintor, dedicándose básicamente a pintar y decorar retablos, así como que estuvo casado con Teresa Jiménez de Cárdenas con la que tuvo varios hijos, uno de ellos ahijado del escultor Torcuato Ruiz del Peral y otro llamado Damián (Gómez Román, 2008: 140)². En cuanto a aquellos que se forjaron un nombre dentro del panorama artístico destaca Domingo Chavarito (1662-1751) (Calvo Castellón, 1975), discípulo de Risueño y artista consolidado a pesar de tener un estilo muy ecléctico, quien pintó en la segunda capilla de la iglesia conventual de Santo Domingo La Huida a Egipto y en una de las estancias del camarín de la Virgen del Rosario La Batalla de Lepanto y Pío V ante la Virgen del Rosario [5] aunque el programa iconográfico de este espacio se completaría, a lo largo de los años, con otros asuntos y otros artistas como Tomás de Medialdea.

La costumbre de revestir los muros fue más allá de los espacios exclusivamente religiosos hacia ámbitos urbanos 
3. Eduardo y Francisco Martínez, Pinturas murales (detalle), 1738

Monasterio de Santa Isabel la Real,

Granada. Foto: J. M. Rodríguez

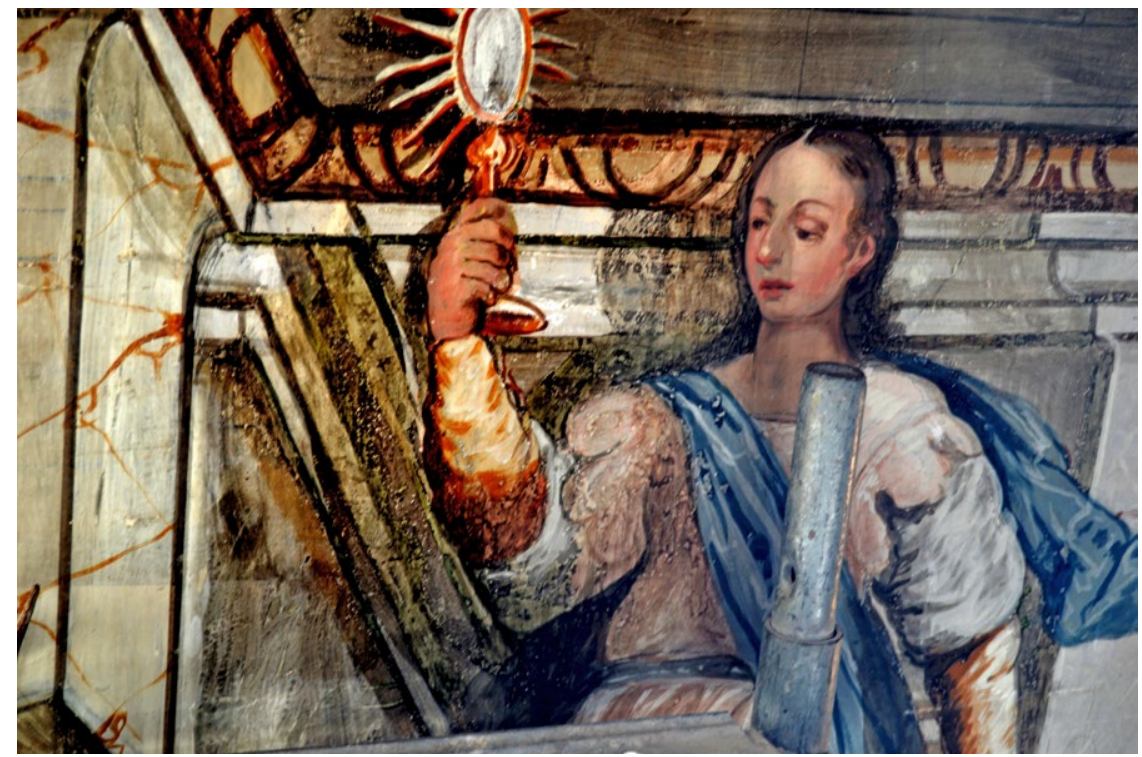

generándose, de este modo, un considerable gusto por la decoración mural sobre todo en las fachadas de las principales casas y palacios granadinos ${ }^{3}$. Sin lugar a dudas, la que lucía las pinturas más llamativas era la casa solariega de los marqueses de Falces, desaparecida a comienzos del siglo XX con la apertura de la Gran Vía, cuyos asuntos sobresalían por su gran originalidad y rareza. El inmueble en cuestión se alzaba en la calle del marqués de Falces, antes Azacayas, y

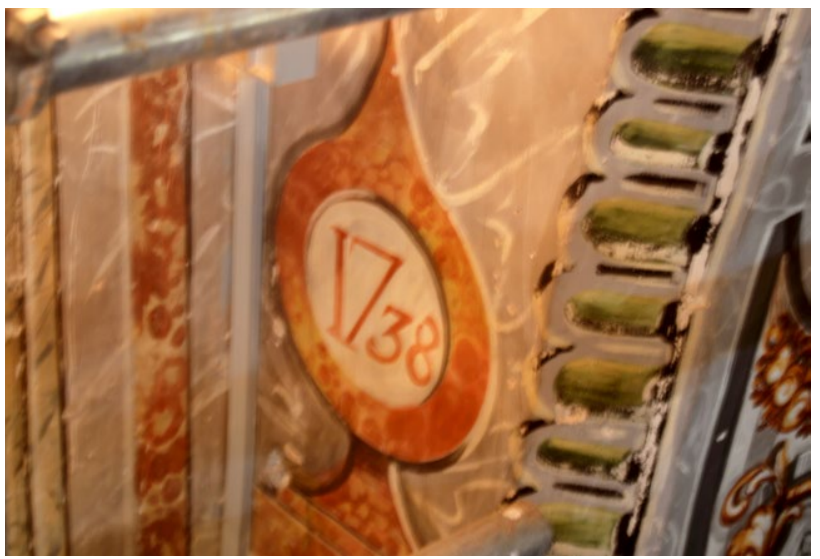

4. Eduardo y Francisco Martínez, Pinturas murales (detalle), 1738. Monasterio de Santa Isabel la Real, Granada. Foto: J. M. Rodríguez presentaba al exterior insólitas pinturas al fresco [6]. Desconocemos por quiénes fueron realizadas pero sospechamos que bien pudieron ejecutarse a comienzos del siglo XIX dado que los asuntos representados parece que fueron extraídos de la edición, revisada en 1806 por José de Asensio y Torres, del libro de Juan de Arfe y Villafañe De varia commensuración. En concreto nos referimos al libro quinto en el que figuran unos grabados con extraños animales originarios de

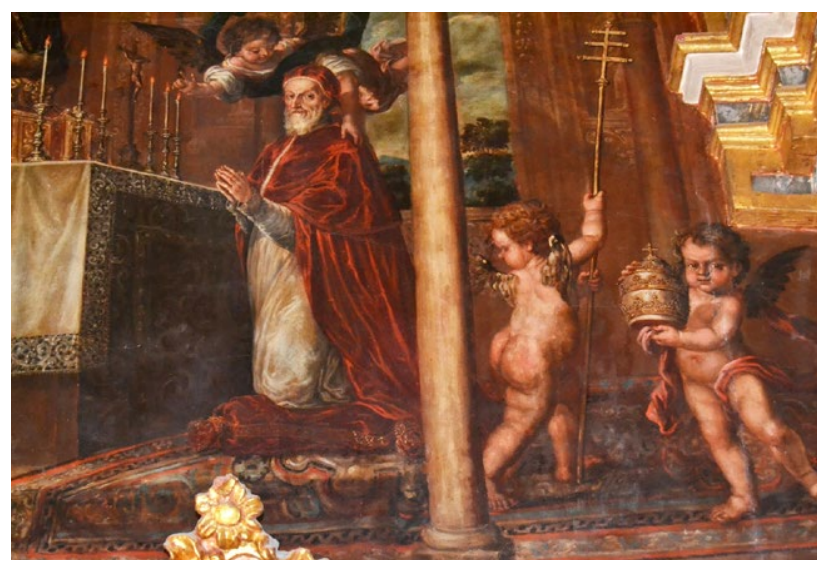

5. Domingo Chavarito, Pío V ante la Virgen del Rosario (detalle). Camarín de la Virgen del Rosario, Granada. Foto: J. M. Rodríguez 


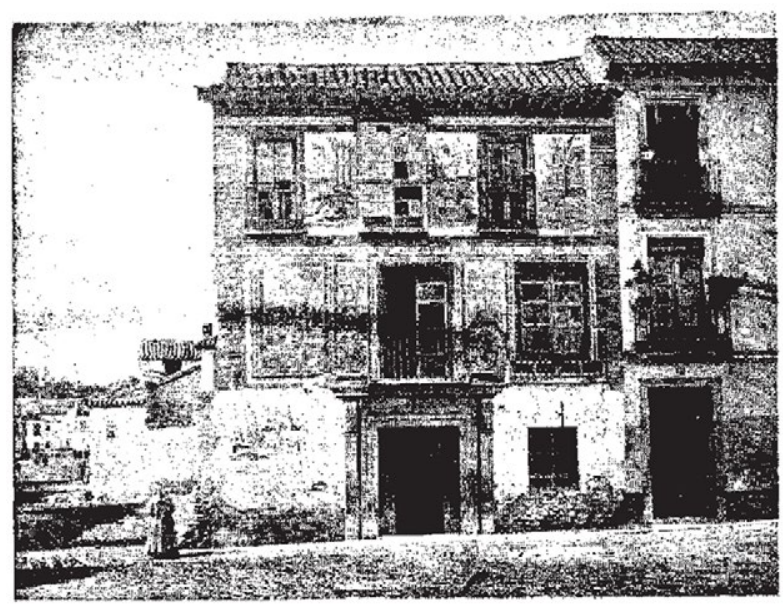

6. Casa solariega del marqués de Falces (desaparecida). Granada. Foto: J. M. Rodríguez

tierras americanas (Asensio y Torres, 1806). Así, en el piso principal, y a ambos lados del balcón central, figuraban dos paisajes con un gris pequeño, o armiño gris, por un lado y por otro un "zartuocya», junto con una tercera escena de una marina. En el segundo piso se evidenciaba un patang, un encubertado y una tercera secuencia con un gran tamandua (Valladar Serrano, 1900: 233-234). Según Valladar: «la ejecución de estas pinturas es muy aceptable, sin que por esto se diga que se trata de una obra de gran mérito»"

Por otra parte, esta moda decorativa se mantuvo más allá del XVIII hasta bien entrada la siguiente centuria dado que imperó, durante bastante tiempo, una cierta tendencia a ornamentar tanto al exterior como el interior de las principales casas solariegas de Granada. De hecho, el antiguo palacio del duque de Gor albergaba algunas estancias, al igual que la fachada, decoradas con pinturas al fresco. Pese a la desaparición de este edificio afortunadamente sí se conservan otros ejemplos de la época, entre ellos algunos inmuebles ubicados en la carrera del Darro (Gárate Rojas, 1996: 127-142. Gallego Roca, 1996: 219-243). Por suerte también se conserva la decoración de la casa señorial de la calle San Matías, actual sede del Colegio Oficial de Aparejadores y Arquitectos Técnicos de Granada, cuyas pinturas han podido ser recuperadas recientemente. En este caso imitan jambas y dinteles que sirven de encuadre de los respectivos vanos mientras que en la última planta se incorporan unos decorativos jarrones. En el ámbito religioso sobresale la deco- ración de la capilla mayor de la albaicinera iglesia de San José pintada por Francisco Aranda Delgado, discípulo del escenógrafo Luis Muriel, en 1830. En ese mismo año Aranda decoró la capilla mayor de la desaparecida iglesia de San Gil (Gómez-Moreno González, 2004: 662).

Aproximación a la vida y obra de los pintores Martín de Pineda, Juan de Medina, José Hidalgo y Diego Sánchez Sarabia

Las grandes empresas artísticas acometidas en Granada en la primera mitad del siglo XVIII fueron el resultado de una cierta estabilidad política y social que la ciudad experimentó gracias a su adhesión, y apoyo, a la nueva monarquía borbónica. En este sentido la remodelación de la basilica de las Angustias fue tomada como un empeño personal tanto por parte de la corona como de un nutrido grupo de promotores

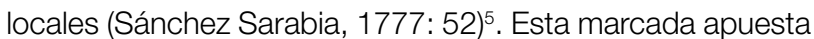
por el barroco ornamental quedó puntualizada en el interior del templo en dos ámbitos muy concretos: el nuevo retablo mayor y el camarín de la Virgen de las Angustias. El programa iconográfico con que se adornaron los muros de este último espacio fue entendido desde fórmulas religiosas pero, a la vez, propagandísticas en torno a la figura de su promotor Juan de Lizana. Por consiguiente, no se escatimaron esfuerzos en convocar a los principales artistas activos de la zona que en el caso de la pintura fueron dos sobresalientes pintores. El primero de ellos fue Juan de Medina cuyos trabajos se circunscriben básicamente al ámbito religioso; y el segundo, José Hidalgo quien, por su parte, gozaba de una considerable fama y prestigio siendo su arte requerido por las principales familias nobiliarias del reino de Granada. Con todo, en la ciudad existieron otros tantos artistas que, ya desde finales del siglo XVII y comienzos del XVIII, ejercitaban la pintura mural con mayor o menor fortuna.

\section{Martín Andrés de Pineda Ponce de León}

El primero al que hacemos referencia es Martín Andrés de Pineda Ponce de León, nacido en Granada en 1684 e hijo de Gabriel de Pineda y Juana Gómez de Vega ${ }^{6}$. Su trabajo más documentado es su participación, en 1729, en La 
Alhambra con motivo de la venida de Felipe $V^{7}$. Ya en abril de ese mismo año estuvo interviniendo en el patio de los Leones percibiendo por ello unos nueve reales diarios y al mes siguiente retocó las pinturas al temple del tocador de la Reina cobrando, en este caso, unos 15 reales. En esta última empresa colaboraron con él los pintores Juan Antonio Coello, Francisco Moreno y Manuel Sanz Jiménez quienes trabajaron en calidad de oficiales (Gómez-Moreno González, 2004: 659). Su particular estilo, en base al empleo de motivos ornamentales asimilados durante su intervención en La Alhambra, le confirió la suficiente habilidad como para afrontar otros cometidos de envergadura como así se constata en los frescos, pintados y firmados en 1729, de la primera capilla del lado evangelio de la iglesia de San Miguel el Bajo y que en su día estuvo bajo la advocación del «Señor del Olvido" " [7]. Por otra parte, a consecuencia de la renovación decorativa emprendida en la década de los veinte en la iglesia del monasterio de San Jerónimo Martín de Pineda se encargó de decorar dos de sus capillas: la capilla familiar del caballero de Santiago Ginés de Carranza y López -corregidor de Loja y caballero Veinticuatro de Granada (1542)donde pintó la Huida a Egipto y la Batalla de la Higueruela; y la capilla del Infantado con las escenas de la Coronación de la Virgen, San Juan en Patmos, La Asunción y San Jerónimo (Gómez-Moreno González, 1982: 367).

\section{Juan Julián de Medina}

Juan Julián de Medina es el otro gran muralista de la primera mitad del XVIII cuyo trabajo, hasta ahora, ha sido poco valorado a pesar de ser tildado por algunos investigadores, entre ellos Gómez-Moreno, de pintor «bueno y seguidor de Lucas Jordán». Nacido en 1680 en la villa de Coín (Málaga) fue bautizado el 3 de febrero en la parroquia de San Juan de dicha localidad como «hijo de la Yglesia» siendo su padrino Juan Rojo. En realidad era hijo extramatrimonial de Hugo de Bourman y Medina, mercader y regidor perpetuo de la ciudad de Vélez-Málaga, y de Petronila Grande. Este hecho, dado lo delicado del asunto, le llevaría a silenciar el nombre de sus progenitores durante bastante tiempo. Aun así, el influyente regidor se lo llevó a Vélez a la edad de un año relegando su crianza a la pareja formada por Josefa Sánchez y Juan de Matías, domésticos suyos. Sin embargo, en

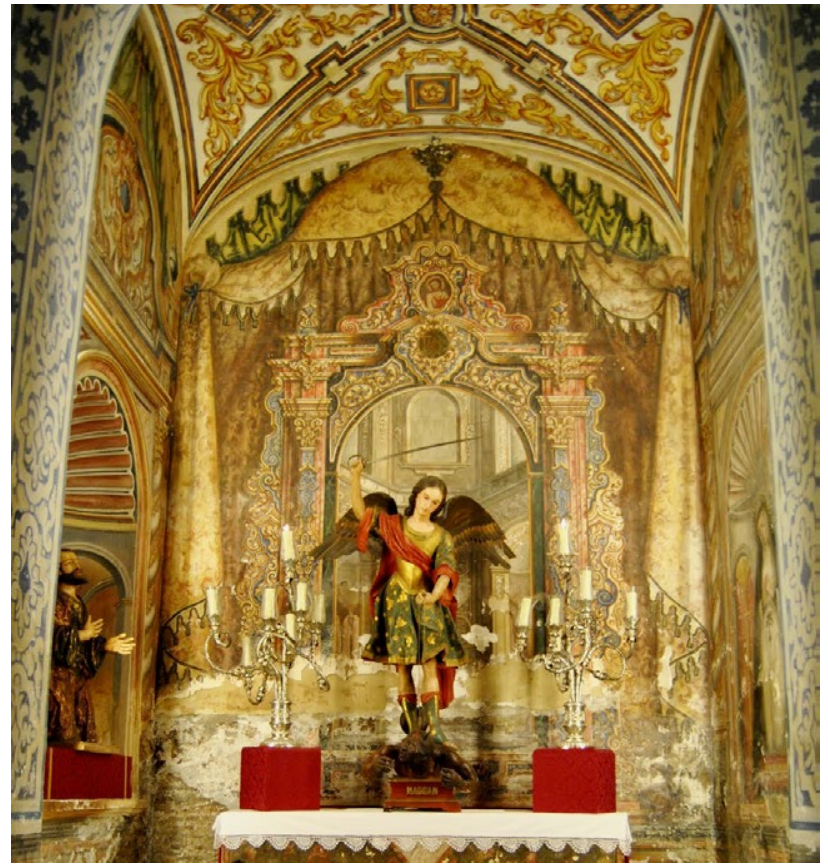

7. Martín de Pineda, Capilla del Señor del Olvido. Iglesia de San Miguel, Granada

1694 Bourman decidió que había llegado el momento de enseñarle un oficio y para ello encomendó su formación al pintor Juan López Molinero, quien se había trasladado a Vélez para participar en la decoración de las fiestas del Corpus celebradas en ese año. Así fue como López Molinero trajo al joven a Granada en 1695 acogiéndolo en su casa taller en la albaicinera parroquia de San José e iniciándolo en la práctica de la pintura. Para Medina esto supondría no solo el aprendizaje de un oficio sino la oportunidad de frecuentar, y conocer, a otros tantos pintores y habituales colaboradores de su maestro, como Juan Antonio Coello -éste activo hasta mediados del XVIII- o Alfonso Vico de Lara. A la edad de 20 años, y una vez encauzada su carrera, contrajo matrimonio con Francisca de Torres Becerra ${ }^{9}$.

Por lo que se refiere a su trayectoria profesional conviene señalar que empezó a sobresalir a comienzos de siglo lo que, a la postre, le posibilitó codearse con otros pintores y personajes relevantes del momento como Jerónimo de Rueda Navarrete, Francisco Rodríguez de la Hinojosa o José Atanasio Bocanegra, hijo del aclamado Pedro Atanasio de Bocanegra. Sin embargo, su crédito se consolidó a partir de 
1712 coincidiendo con el respaldo que le brindó el arzobispo Martín de Ascargorta así como gran parte de su entorno, en especial el mayordomo arzobispal Jerónimo Calvo de Molina y el presbítero José de Riscos. Fue de esta manera como en 1714 se vio con el suficiente respaldo como para dar fe de su condición de hijo natural, lo que nos revela que por esos años ya era notorio tanto su origen como su posicionamiento social. A pesar de ello recayeron ciertas sospechas sobre su condición religiosa, y la de su esposa, por parte del tribunal de la Inquisición hasta el punto que fue acusado de morisco en $1723^{10}$. Dicha inculpación se amplió a la de molinista en el Auto de Fe de 4 de marzo 1731 siendo, finalmente, reconciliado ad vehemendi (Caro Baroja, 1986: 128). Con todo, pudo seguir desempeñando su oficio a pesar de que para el año 1743 aún no había satisfecho la cantidad que debía al fisco en concepto del secuestro de sus bienes, incluyendo un pleito pendiente con las monjas del convento de Santa Clara de Loja en cuya iglesia intuimos que estuvo trabajando en el ciclo de sus pinturas murales ${ }^{11}$. Son escenas relativas a la exaltación de la Virgen y Cristo, envueltas en arquitectura fingida y trampantojos, y episodios de la vida de san Francisco y santa Clara, santos de la orden franciscana y arcángeles ${ }^{12}$.

A pesar del peliagudo proceso anteriormente reseñado, y que en cierta manera ralentizó parte de sus cometidos, en 1723 inició su primer encargo de gran envergadura. Se trata de la decoración mural de la iglesia del monasterio de San Jerónimo y que se prolongó en los años de 1727, 1729 y 1735. Su intervención se remite a Cristo arrojando a los mercaderes del Templo, San Pedro curando a un enfermo, la Crucifixión y los Padres de la Iglesia así como a los grupos de ángeles y angelillos que aparecen repartidos por los pilares y las bóvedas del templo [8]. A juicio de Gómez-Moreno «merecen particulares elogios su colorido y composición, el buen gusto de los adornos y la agradable disposición del conjunto» (Gómez-Moreno González, 1982: 366). Sin embargo, avanzado el siglo XVIII este conjunto mural no fue del todo bien celebrado: «la iglesia y el coro está pintado al fresco por borrones de la obra de Jordán» (Salas, 1963: 160). Por otra parte, si atendemos a las referencias bibliográficas aportadas por el erudito José Giménez-Serrano la participación de nuestro pintor en San Jerónimo, cuyo coste total de las pinturas fue de cien mil reales, estuvo bajo la dirección de «un lego carmelita descalzo que vino de Madrid con este objeto» (Giménez-Serrano, 1846: 277). A todo ello, su labor como muralista tuvo su continuidad en otros espacios religiosos como la colegiata de San Pablo, actual parroquia de los Santos Justo y Pastor, donde los hermanos jesuitas le encargaron pintar, en el arranque de la bóveda principal, los pasajes de la vida de san Francisco Javier (Gómez-Moreno González, 2004: 659); o en las pinturas al fresco de los costados del presbiterio del desaparecido convento de Carmelitas Calzados (Gallego Burín, 1991: 213).

Con todo, uno de sus trabajos más acreditados está relacionado con el encargo que le hizo el licenciado y clérigo Juan de Lizana quien, en 1741, le encomendó completar la decoración mural, iniciada por José Hidalgo en 1739, del camarín de la Virgen de las Angustias. Más adelante, en 1743, pintó el nicho del coro del convento de las Agustinas de Granada y al año siguiente restauró las tablas flamencas de la colección de la Reina Isabel de la Capilla Real, por las que cobró 1.000 reales, y pintó las puertas de los sagrarios del retablo principal y del retablo de la Santa Cruz del citado templo, percibiendo en este caso unos 140 reales $^{13}$. A partir de esa fecha carecemos de datos documentales sobre su vida y obra aunque sabemos que también cultivó la pintura al óleo de la que conservamos algunos ejemplos como La Virgen de las Mercedes (Universidad de Granada) o El árbol genealógico de la orden realizado para los hermanos de San Juan de Dios (Gómez-Moreno González, 1982: 361). También en el museo conventual de carmelitas descalzas de San José de Antequera, y procedente de su iglesia, se conserva un lienzo de la Sagrada Familia de su mano (Romero Benítez, 1989: 108).

\section{José Hidalgo}

El otro artista que desempeñó un destacado papel en el ámbito de la pintura mural fue José Lacque Hidalgo. Hijo de Francisco Lacque Hidalgo, de origen francés, y Mariana Cano, nacido el 21 de enero de 1711 en la localidad granadina de Guadahortuna ${ }^{14}$. Siendo aún de corta edad la familia decidió instalarse en Granada lo que posibilitó que nuestro joven artista se iniciara en los rudimentos de la pintura sin que hasta la fecha sepamos quién fue su maestro. De gran «abilidad en el Arte de la pintura» instaló su taller en el Albaicín estableciendo vínculos de carácter laboral con otros 
pintores entre los que se encontraban Salvador de Marchena, artista de trayectoria desigual, y por otro lado Luis Sanz Jiménez. El 18 de septiembre de 1734 contrajo matrimonio en la parroquia de San Miguel con Manuela Castellanos, hija de Jerónimo Castellanos y Ana Bonal ${ }^{15}$. Sin embargo, poco le duraría la felicidad al matrimonio ya que el 21 de agosto de 1737 falleció, inesperadamente, su esposa ${ }^{16}$.

A pesar de este contratiempo fueron años bastante fructíferos en lo profesional convirtiéndose de este modo en uno de los pintores más sobresalientes de Granada. Por este motivo decidió trasladar su taller al centro de la ciudad, coincidiendo con el encargo más importante de toda su carrera artística. Nos referimos al ciclo mural ideado para el nuevo camarín de la basílica de las Angustias en el que estuvo trabajando entre los años 1739 y $1741^{17}$. Se trata de un acertado programa iconográfico organizado en base a lemas y epigramas escritos en latín y octavas en castellano. Así en el antecamarín, encima de la puerta dentro de un óvalo, figuran escenas de La Anunciación, El arcángel Rafael y Lucifer y repartidos por el resto de la estancia aparecen representados Jesús buen Pastor, Adoración de los magos, Circuncisión de Cristo, Jesús ante el sanedrín, Niño Jesús en el templo, Aparición del ángel a José, Presentación de Jesús en el templo, Niños Jesús en Brazos de San Antonio y Soneto a Juan de Lizana (benefactor de la hermandad). Mientras que las paredes del postcamarín quedaron reservadas para el relato de la pasión de Cristo: María se despide de Jesús, La Virgen atravesada por una daga y La flagelación de Cristo, Camino del Calvario, La Lanzada, Descendimiento de la Cruz. El ciclo se completa con San Jerónimo en el desierto, El encuentro de Jesús y la samaritana, y Magdalena arrodillada ante la cruz. Tanto las paredes del antecamarín como las del postcamarín lucen además un coro de angelitos portando los símbolos de la pasión.

\section{Diego Sánchez Sarabia}

El versátil Diego Sánchez Sarabia, nacido en Granada en 1704, cultivó al mismo nivel tanto la escultura como la pintura. Sus primeros trabajos significativos los realizó a partir de 1725 fuera de la ciudad de la Alhambra teniendo como escenario el monasterio de la Cartuja del Paular en Rascafría donde había acudido como integrante del equipo del ima-

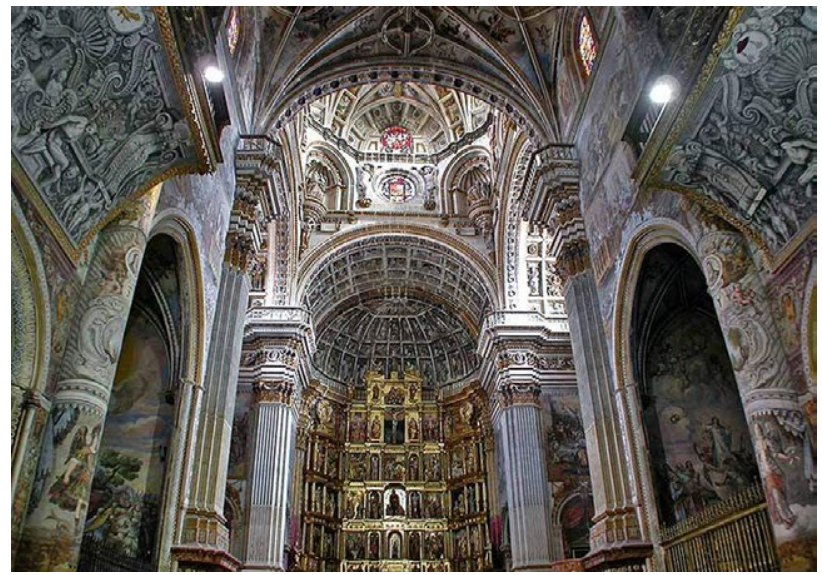

8. Pinturas murales. Iglesia del Monasterio de San Jerónimo, Granada. Foto: J. M. Rodríguez

ginero lojeño José Ramio Ponce de León (Gómez Román, 2011: 83-94). Durante ese año, y el siguiente, tanto Ramiro como Sarabia, junto con el resto de colaboradores granadinos, auxiliaron al afamado escultor sevillano Pedro Duque Cornejo en la decoración cartujana hasta el año 1727. Finalizado este compromiso Sánchez Sarabia regresaría a Granada donde formó familia, dos años más tarde, con Ana Antonia Romero. Para entonces ya era un escultor de cierto prestigio, circunstancia que, a la postre, le permitiría acometer sus primeras obras en el campo de la pintura e incluso ensayar el arte del buril al lado del grabador de láminas Antonio Sánchez de Ulloa.

A partir de 1760 comenzó su vinculación a la Real Academia de Bellas Artes de San Fernando, para la que realizó la copia de las pinturas de la Sala de los Reyes y los cortes y alzados del palacio de la Alhambra (Rodríguez Ruiz, 1990: 225-257) y fue nombrado perito por arquitectura y dibujo por la Real Junta de Excavaciones para la inspección de los descubrimientos de la Alcazaba (Orfila, Sotomayor, Sánchez, Marín, 2012: 118-119). De igual modo se convirtió en el primer pintor granadino distinguido por la Real Academia de Bellas Artes de San Fernando como académico supernumerario el 12 de noviembre de 1762 por el lienzo San Fernando recibe la embajada del rey de Fez (Ceán Bermúdez, 1800: 341-342). De igual modo, fue uno de los principales artífices de la fundación, en la ciudad, de la Escuela de Tres Nobles Artes -después Ilamada Escuela de Dibujo y 
finalmente Academia de Bellas Artes- en 1777 (Gómez Román, 2012a: 117-121). El deseo de Sarabia era desterrar el aprendizaje de taller en favor de una enseñanza racionalizada, y dirigida, con un método docente que abarcase el estudio de las principales disciplinas artísticas ${ }^{18}$.

A pesar de esta apuesta ilustrada, Sarabia fue un artista más bien cercano a la estética barroca como se aprecia en su trabajo para la basílica de San Juan de Dios en Granada y en especial en el ciclo de lienzos alusivos a la vida del santo que adorna las paredes del patio principal de su hospital. Para ello tomó como referencia algunas estampas, tal y como se aprecia en las pechinas de la basílica cuyas pinturas están inspiradas en las de Domenichino para la romana iglesia de Sant'Andrea della Valle. También decoró al óleo la sacristía de dicho templo con un programa iconográfico basado en la Gloria celestial mientras que en la cúpula del camarín representó la Jerusalén celeste con San Juan de Dios recibiendo su recompensa por su labor asistencial (Larios, 204: 113). Finalmente falleció en la localidad almeriense de Fondón, tras sentirse indispuesto, el 6 de abril de 1779. Se había instalado en esta localidad, arropado por el hacendado local Juan Antonio Ramírez, en 1778 para pintar el camarín del Cristo de la Luz de la iglesia parroquial de San Andrés (Sánchez Real, 2007: 891-924). En su cúpula representó al óleo al Padre Eterno y la Asunción de la Virgen rodeada de ángeles mientras que en las pechinas simuló ángeles con los atributos del martirio.

\section{La consolidación de la pintura decorativa}

Por lo que se refiere a la pintura decorativa conviene matizar que alcanzó un especial desarrollo a partir de la década de los treinta coincidiendo con el exorno de nuevos espacios y edificios ${ }^{19}$. La nueva estética basada en el empleo de elementos puramente ornamentales como rocallas, florones, guirnaldas, aves y animales exóticos, etc., evidenciaba un nuevo uso decorativo propio del rococó. No pasa desapercibido que esta nueva apuesta artística vendría a coincidir con la llegada de Felipe $\mathrm{V}$ a tierras granadinas que, si bien tuvo una estancia corta desde el 23 de marzo de 1730 hasta el 5 de junio de ese mismo año, revolucionó a lo más granado de la sociedad. Surgió, pues, una conciencia, promovida por ciertas instituciones y determinados particulares, encamina- da a la ejecución de nuevas obras que estuvieran acordes a una modernización de la urbe. En esta dinámica de erigir nuevos edificios, paralela a la renovación de edificios preexistentes, nos encontramos con el empeño de ciertos personajes como el padre general de la orden de San Juan de Dios fray Alonso de Jesús y Ortega que decidió levantar una nueva basílica y renovar el antiguo hospital de la orden. Es por ello que fue en el ámbito de la Iglesia donde se difundió ese nuevo gusto tendente a la exageración decorativa. Para llevar a cabo dicho programa el padre Ortega puso especial énfasis en solicitar la colaboración de artistas y arquitectos de renombre. Por ello para la traza de la basílica contó con la colaboración de José de Bada mientras que para su amueblamiento y decoración seleccionó un elenco bastante numeroso de escultores, pintores, doradores, etc. (Larios, 2004). Entre ellos se encontraba el pintor fresquista Tomás Ferrer quien emplearía en las paredes de camarín un rico lenguaje decorativo cargado de gracia y encanto.

El expresado artista había nacido a comienzos de siglo en Zaragoza donde inició su formación como pintor especializándose en la pintura decorativa. Sin embargo, alentado por las nuevas posibilidades laborales que le ofrecía la ciudad de Granada decidió instalarse en esta población en la década de los treinta. De esta manera se convirtió en uno de los primeros artistas que desarrolló su arte dentro de la estética del rococó al idear todo un lenguaje decorativo de escenas bíblicas, paisajes, frutas, flores y grutescos pintados al fresco en las paredes del claustro del hospital de San Juan de Dios para acompañar a los lienzos sobre la vida del santo pintados por Diego Sánchez Sarabia. De igual modo, empleó ese mismo lenguaje ornamental en las bóvedas de las capillas colaterales de la basílica. Por otra parte, en las paredes del antecamarín simuló, mediante una técnica mixta de temple y óleo, elementos vegetales como complemento de los estucos tallados y dorados que figuran también en las paredes mientras que en el postcamarín ese rico lenguaje floral lo completó con un zócalo pintado con arquitectura fingida y bustos de la antigüedad, exóticas aves y ricos cortinajes en las paredes (Larios, 2004: 114-117). También intervino en la sacristía de la Cartuja decorando su bóveda en 1753 en torno a la figura de san Bruno. Con todo, Ferrer tanteó otros géneros y técnicas lo que le permitió experimentar con las vistas urbanas de la ciudad y de la que mencionamos la que realizó en 1751 sobre el río Genil. 
En 1760, y una vez completados sus encargos en Granada, se trasladó a la localidad cordobesa de Lucena, a instancias de la propia orden hospitalaria, para participar en el programa decorativo de la iglesia juandediana. Así, en el interior de dicho templo decoró las tribunas con escenas relativas a La Anunciación y La Visitación. Gracias a este trabajo se incorporó al elenco de artistas que estaba trabajando en el camarín de la ermita de la Virgen de Araceli de dicha localidad. En sus muros pintó en 1761 un coro celestial envuelto en guirnaldas, flores, frutas y paisajes bíblicos. Dado que para entonces gozaba de cierta fama se desplazó a Écija con la encomienda de decorar el palacio de los marqueses de Peñaflor. Lo que prometía ser una de sus obras culminantes se tornó en un lastre para el pintor puesto que pronto, en concreto en 1763, se granjeó fama de destemplado «pues sacándolo de quatro ramajos sin método, no ay más havilidad, y asimismo, no se sabe cómo tratar con él para que cumpla el trato, pues todo es hablar y passar el tiempo, y crucificar a el que le pide, pues han salido en Lucena tan hartos, que no quieren más a don Thomás» (Martín Ojeda-Valseca Castillo, 2000: 168). Finalmente las pinturas con paisajes y «trompe l'oeils» que adornan el largo balcón corrido de la fachada fueron rematadas, entre 1764 y 1765 , por el pintor madrileño Antonio Fernández.

\section{La pintura profana y las hazañas del Quijote en el Palacio del Cuzco en Víznar}

Ya a finales de siglo advertimos un cambio de gusto en cuanto a los modelos decorativos siendo el mejor exponente el ciclo del Quijote del palacio arzobispal del Cuzco, emplazado en la localidad granadina de Víznar. Dicho edificio fue una antigua heredad arzobispal remodelada en 1795 por Juan Puchol, maestro mayor del arzobispado, a instancias del arzobispo peruano Juan Manuel Moscoso (1723-1811). El conjunto se decoró con pinturas murales al temple: abarcando las galerías del jardín, escaleras, crujías así como la zona de acceso junto a la llamada Puerta de los Carros ${ }^{20}$. De todo el conjunto la parte más original es la que da al jardín donde se observa la contraposición de dos gustos estéticos en su exterior. Por un lado, las escenas pastoriles y campestres revelan el apego que el prelado tenía con respecto a la estética tardobarroca; mientras que las figuras y personajes del mundo clásico, junto con las escenas del Quijote, lo sitúan en la perspectiva historicista del Siglo de las Luces. En este último caso a la hora de la elección del tema influyó la aparición de dos libros. El primero de ellos la Vida y hechos del ingenioso caballero Don Quixote de la Mancha (Madrid, 1777), impresa por Antonio Sancha y dividida en cuatro volúmenes con grabados de Monfort sobre dibujos de José Camarón; y el segundo, la edición El ingenioso hidalgo don Quijote de la Mancha (Madrid, 1780), dada a la luz por Joaquín Ibarra y cuidada por la Real Academia Española e ilustrada por distintos artistas (Báez, 2006: 149-167. Calvo Serraller, 1978).

Las escenas murales del Quijote, si bien están realizadas con cierta torpeza, vienen a constituirse, dentro del ámbito hispano, en una de las primeras representaciones murales alusivas a tan particular héroe. En este caso todas las historias cervantinas, que como hemos mencionado están copiadas con ligeras variantes de las estampas de la edición de lbarra, están enmarcadas en decorativas orlas que refuerzan su carácter narrativo. Presentan en la parte inferior su correspondiente leyenda alusiva, si bien algunas están bastante deterioradas, a los siguientes episodios: Pierde el juicio don Quijote con la lectura de los libros de caballería y resuelve hacerse caballero andante; Los yangüeses apalean a don Quijote y Sancho Panza; Mire vuestra merced, señor caballero andante, que no se le olvide lo que de la ínsula me tiene prometido; Segunda salida de don Quijote y Sancho; Sancho Panza arrodillado presenta a don Quijote a la encantada Dulcinea; Pide Dorotea a don Quijote le libre del gigante Pandafilando; Brava y descomunal batalla de don Quijote con unos cueros de vino; El bachiller Sansón Carrasco se ofrece como escudero; Aventura de los molinos de viento; Aventura del yelmo de Mambrino; Aventura de la cueva de Montesinos y Don Quijote colgado de la ventana. El programa iconográfico, por tanto, hace alusión a las aventuras y extravíos del alma humana, los desengaños del corazón y la caída de nuestras ilusiones [9].

Los artífices de dichas pinturas fueron los pintores Antonio Jiménez, nacido en 1749, José Medina, natural de Jaén (ca. 1738) pero avecindado en Granada donde trabajó como pintor decorador y Nicolás Martínez Tenllado que además de dedicarse a la pintura regentaba un lucrativo negocio de chamarilería, donde habitualmente pintaba muebles y restauraba todo tipo de obras. A pesar de ser 


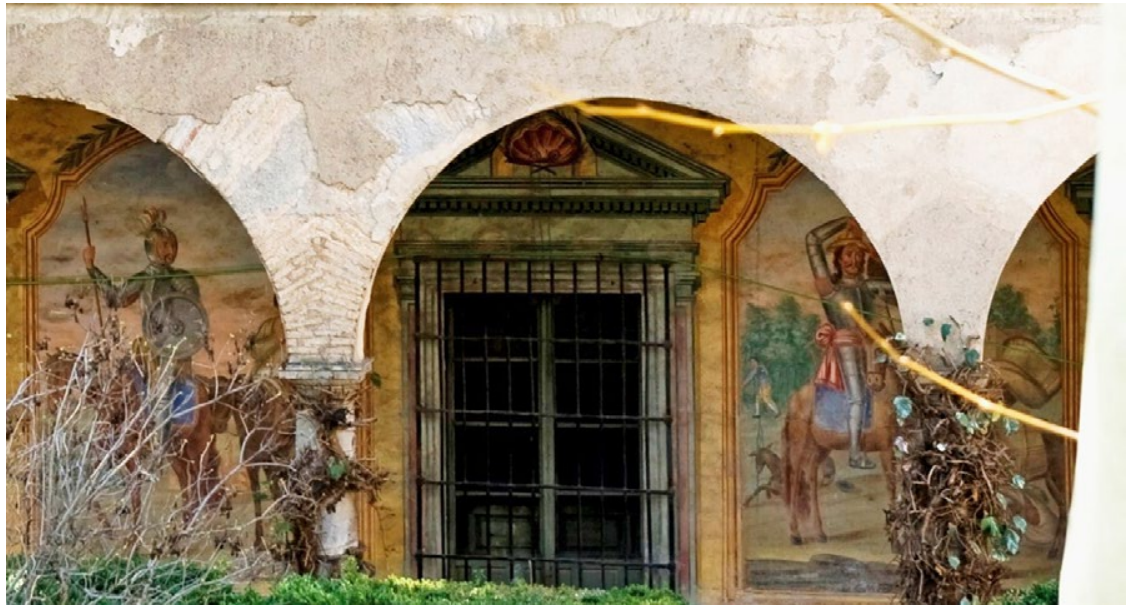

9. Antonio Jiménez, José Medina, Nicolás Martínez Tenllado, Las hazañas del Quijote, 1795. Palacio del Cuzco, Víznar (Granada). Foto: J. M. Rodríguez artistas poco acreditados, y de escasa fortuna, su intervención en las pinturas murales del palacio del Cuzco queda compensada por tratarse de uno de los escasos ejemplos de ciclos pictóricos murales setecentistas de carácter civil conservados en Andalucía. Un asunto profano con un com- ponente ético, las facultades y extravíos del alma humana, impuesto expresamente por el arzobispo Moscoso para su propio deleite y el de sus más allegados (Gómez Román, 2012b: 62-77). Una representación apenas sin precedente en lo que a ornato se refiere.

\section{Notas}

1 Recientemente se ha cometido la restauración de las mismas. La puerta reglar de este monasterio conservaba una hermosa portada fingida destruida casi en su totalidad en las intervenciones de finales del siglo pasado.

http://www.fundacionmontemadrid.es/uploads/area/ff1566071d7754491a4a6064e794c9c18fb4ea0d.pdf.

2 Archivo Histórico Provincial, Granada (AHP, Granada). Catastro. Respuestas vecindario secular. Libro 1259.

3 Es interesante los casos de pintura mural de otras poblaciones vecinas como Sevilla o Málaga. Quiles García, 1986: 63-75. Camacho Martínez-Asenjo Rubio, 1986: 63-75. Camacho Martínez, 2011: 177. A nivel general Gómez Urdañez, 2013.

4 Por aquel entonces Valladar menciona, además de esta otras casas con pinturas, una en la calle de Santa Ana, la del duque de Gor en la plaza de los Girones y otra en plaza Larga.

5 Destaca la protección de Fernando VI y Bárbara de Portugal a la Hermandad de la Virgen de las Angustias y cuyos retratos figuran en la cabecera de la iglesia.

6 Hijo de Gabriel de Pineda y Juan Gómez de Vega. En 1712 desposó con Josefa de Roa.

7 En alguna de sus intervenciones se auxilió de su hijo Ramón.

8 En ese mismo templo también se conserva una rica decoración mural que simula un retablo en lo que en su día fue capilla del Cristo de la Redención.

9 Archivo Histórico Diocesano, Granada (AHD, Granada), auto matrimonio entre Juan de Medina y Francisca de Torres, Granada 21 de febrero 1699. La joven en cuestión había nacido en 1677, era hija de Juan de Torres -natural de Colmenar- y Mariana Becerra -oriunda de Jimena-, y se había criado entre las parroquias de San José y San Miguel. El matrimonio vio compensado su unión con el alumbramiento de numerosos vástagos: José Francisco (1700), María Melchora (1701), Tomás Francisco (1702), Juan Francisco (1703), José Gabriel (1708), Florencia (1710), José Jerónimo (1713), Francisca Lázara (1714), María (1716), Manuela Catalina (1717) y Joaquín Pedro (1719).

10 (AHP, Granada), Fondo Inquisición. Relación de presos 1721-1749, 4509-13.

11 (AHP, Granada), Fondo Inquisición, Cargo, secuestro y confiscación de bienes del pintor Juan de Medina, 1743. Leg. 3166-35.

12 Las pinturas fueron atribuidas, sin base documental, a José y Vicente Cieza por Pascual Madoz sin sopesar que la decoración se pudo prolongar en el tiempo con la participación de otros pintores (MADOZ, 1847: 362). Dicha atribución es compartida por Castañeda Becerra (Castañeda Becerra, 200: 71-76, 137-168). Entre las escenas representadas figuran: Los Desposorios de la Virgen, La Muerte de San José, La Anunciación, La Adoración de los Magos, La Visitación, La Huida a Egipto, La Purificación, El Descendimiento, La Coronación de la Virgen, Jesús entre los doctores, La Inmaculada, Cristo camino del Calvario, San José y María buscan posada en Belén, Santa Ana enseña a leer a la Virgen... A estas narraciones le acompañan otras como la Visión de san Francisco, Santa Clara expulsa a los sarracenos de Asís o santos como san Buenaventura y santo Domingo. 
13 Archivo Capilla Real, Granada (ACR, Granada), leg. 209, Cuentas de Orfebrería 1706.

14 El padre procedía de Ganac y la madre había nacido en Montejícar. José Hidalgo fue bautizado el 29 de enero en la iglesia parroquial de Nuestra Señora de la Concepción. (AHD, Granada), Expediente matrimonial de José Hidalgo con Manuela Castellanos, mic. $1325822,61$.

15 Archivo de la Parroquia de San José, Granada (APJ, Granada), Libro de desposorios de San Miguel, 6. 1723-1761, fols. 70 y 75. Dados los enormes compromisos del novio, quien por esas fechas se relacionaba con lo más granado de la sociedad, se casaron sin las correspondientes amonestaciones y un año después, el 9 de noviembre de 1735, fueron velados siendo los padrinos José de la Torre y Jacinta Muñoz.

16 (APJ, Granada), Libro de defunciones San Miguel 1724-1754, 7, fol. 84 v.

17 Estas estancias fueron pasto del incendio de 1916.

18 Archivo del Instituto Gómez-Moreno de la Fundación Rodríguez Acosta, Granada (AIGM, Granada), Leg. CXXXI, fol. 3

19 Con todo, antes de esta tendencia hubo artistas dedicados a embellecer ciertos espacios simplemente añadiendo elementos de carácter propagandístico como Pedro Moreno quien en 1720 pintó un escudo real para la puerta de la Justicia de La Alhambra.

20 En este caso, aunque muy deterioradas, representan una arquitectura fingida.

\section{Bibliografía}

ASENSIO Y TORRES, José (1806), De varia commesuracion de Juan de Arfe y Villafañe, natural de Leon, y escultor de ora y plata. Tomo II. Tratado de las dimensiones, coloridos, y algunas propiedades de los animales quadrupedos mas principales y raros asi terrestres como anfibios, Imprenta Real, Madrid.

BÁEZ, Eduard (2006), «La gran edición del Quijote de Ibarra (1780). Las estampas grabadas por Jerónimo Antonio Gil, Joaquín Fábregat, Rafael Ximeno y Fernando Selma», Anales del Instituto de Investigaciones Estéticas, n. ${ }^{\circ}$ 88, pp. 149-167.

CALVO CASTELLÓN, Antonio (1975), "Chavarito, un pintor granadino (1662-1751)», Cuadernos de Arte de la Universidad de Granada, n. ${ }^{\circ}$ 12, pp. 217-338.

CALVO SERRALLER, Francisco (1978), Ilustraciones al Quijote de la Academia: por varios dibujantes y grabadores en la imprenta de Joaquín Ibarra, Madrid 1780, Turner, Madrid.

CAMACHO MARTíNEZ, Rosario y ASENJO RUBIO, Eduardo (2001), «Territorio de signos y lenguajes de la ciudad de Málaga: la pintura mural», PH. Boletín del Instituto Andaluz del Patrimonio Histórico, n. ${ }^{\circ} 34$, pp. 200-218.

CAMACHO MARTíNEZ, Rosario (2011), «Un legado patrimonial en continua recuperación: pinturas murales de Málaga», en FERNÁNDEZ GARCÍA, Ricardo (coord.), Pulchrum: scripta varia in honorem María Concepción García Gainza, Gobierno de Navarra, Pamplona, pp. 177-183.

CARO BAROJA, Julio (1986), Los judios en la España moderna y contemporánea, Istmo, Madrid.

CASTAÑEDA BECERRA, Ana María (2000), Los Cieza, una familia de pintores del Barroco granadino: Juan, José y Vicente, Universidad, Granada.

CEÁN BERMÚDEZ, Juan Agustín (1800), Diccionario de los más ilustres profesores de las Bellas Artes en España, Viuda de lbarra, Madrid. FERRER MORALES, Ascensión (1998), La pintura mural. Su soporte, conservación, restauración y las técnicas modernas, Universidad, Sevilla. GALLEGO BURíN, Antonio (1991), Guía de Granada, Comarex, Granada.

GALLEGO ROCA, Javier (1996), «La restauración arquitectónica y los colores de Granada», en GALLEGO ROCA, Javier, Revestimiento y color en la arquitectura: conservación y restauración, Universidad de Granada, Granada, pp. 219-243.

GÁRATE ROJAS, Ignacio (1996), «Una experiencia de color en la Carrera del Darro», en GALLEGO ROCA, Javier, Revestimiento y color en la arquitectura: conservación y restauración, Universidad de Granada, Granada, pp. 127-142.

GIMÉNEZ-SERRANO, José (1846), Manual del artista y del viagero en Granada, J. A. Linares, Granada.

GÓMEZ-MORENO GONZÁLEZ (1982), Manuel, Guía de Granada, Universidad-Fundación Rodríguez-Acosta, Granada.

- (2004). Obra dispersa e inédita, Fundación Rodríguez-Acosta, Granada.

GÓMEZ ROMÁN Ana María (2008), "Los lances de un hombre y la fortuna de un artista: nuevas noticias sobre Ruiz del Peral», Boletín del Centro de Estudios Pedro Suárez, n. ${ }^{\circ} 21$, pp. 213-274. 
GÓMEZ ROMÁN, Ana María (2011), "Contribución al estudio de la escultura andaluza del siglo XVIII. Pedro Duque Cornejo y su estela en Granada», en AA. W., Docta Minerva. Homenaje a la profesora Luz de Ulierte, Universidad de Jaén, Jaén, pp. 83-94.

- (2012a), «Artistas y anticuarios en las falsificaciones del Albaicín», en SÁNCHEZ LÓPEZ, Elena; MARÍN DÍAZ, Purificación y GÓMEZ ROMÁN, Ana María, En torno a la Granada falsificada, Diputación de Granada, Granada, pp. 117-121.

- (2012b), «Retrato de un arzobispo criollo: el Palacio del Cuzco (Víznar, Granada)», Revista Quiroga, n. 2, pp. 62-77.

GÓMEZ URDÁÑEZ, Carmen (coord.) (2013), Sobre el color en el acabado de la arquitectura histórica, Prensas Universitarias, Zaragoza.

LARIOS, Juan (2004), El hospital y la basílica de San Juan de Dios, Diputación de Granada, Granada.

MADOZ, Pascual (1847), Diccionario geográfico-estadístico-histórico de España y sus posesiones de Ultramar, tomo 10, Madrid.

MARTíN OJEDA, Marina y VALSECA CASTILLO, Ana (2000), Écija y el Marquesado de Peñaflor, de Cortes de Graena y de Quintana de las Torres, Fundación Marqueses de Peñaflor, Écija.

ORFILA, Margarita; SOTOMAYOR, Manuel; SÁNCHEZ, Elena y MARÍN, Purificación (2012), La Granada "falsificada»: el pícaro Juan de Flores, Diputación de Granada, Granada.

QUILES GARCÍA, Fernando (1996), «La policromía de fachadas en la arquitectura sevillana», Atrio, 8-9, pp. 63-75.

ROMERO BENÍTEZ, Jesús (1989), Guía artística de Antequera, Caja de Ahorros de Antequera, Antequera.

RODRÍGUEZ RUIZ, Delfín (1990), «Diego Sánchez Sarabia y las Antigüedades Árabes en España: los orígenes del proyecto», Espacio, Tiempo y Forma, n. ${ }^{\circ}$ 3, pp. 225-257.

SALAS, Xavier de (1963), Noticias de Granada reunidas por Ceán Bermúdez, Universidad de Granada, Granada.

SÁNCHEZ REAL, Javier (2007), "Diego Sánchez Sarabia y las pinturas murales del camarín del Cristo de la Luz de Fondón (Almería)", en SÁNCHEZ RAMOS, Valeriano (coord.), Lux Mundi. La religiosidad popular en torno a la Luz, Instituto de Estudios Almerienses-Asociación Cultural Talia, Almería, pp. 891-924.

SÁNCHEZ SARABIA, Diego (1777), Compendio historico del origen y culto en Granada de N. Señora de las Angustias, Imprenta Santísima Trinidad, Granada.

VALLADAR SERRANO, Francisco de Paula (1900), «Los derribos de la Gran Vía», La Alhambra, n. 58, 31 de mayo, pp. $233-234$. 